\title{
Abandono, reprovação, reforço escolar: respostas de diretores ao questionário contextual da Prova Brasil
}

\author{
School dropout, failure rates, reinforcement classes: directors' responses to \\ the contextual questionnaire of Prova Brasil \\ Abandono, reprobación, refuerzo escolar: respuestas de directores al \\ cuestionario contextual de la Prova Brasil \\ GISELLE CRISTINA MARTINS REAL \\ JOSÉ DA SILVA SANTOS JUNIOR \\ SANDRA MARIA ZÁKIA LIAN SOUSA \\ ANGELA MARIA MARTINS \\ MARIA HELENA DE AGUIAR BRAVO
}

\begin{abstract}
Resumo: São apresentados resultados de pesquisa que caracterizou iniciativas de diretores municipais do Ensino Fundamental, via questionário contextual da Prova Brasil 2015, no que tange ao controle do abandono, reprovação, acompanhamento da frequência e ações de reforço escolar. O tratamento estatístico delineou o cenário nacional no que se refere às práticas declaradas por esses diretores, em interlocução com estudos da área. Os dados indicam existência de ações para enfrentamento do tema que, contudo, ainda apresenta índices desafiadores em relação ao abandono e à reprovação em escolas municipais.
\end{abstract}

Palavras-chave: Abandono e reprovação escolar; Ações de reforço; Diretores municipais; Questionário contextual; Prova Brasil.

\begin{abstract}
This research presents initiatives of municipal directors of elementary schools, through a contextual questionnaire of the Prova Brasil 2015, regarding the control of school dropout, failure rates, frequency monitoring, and school reinforcement classes. The statistical treatment delineated the national scenario regarding the practices declared by these directors, in interlocution with studies of the area. The data indicates the existence of actions to address the theme, which however still presents challenging indices in relation to abandonment and disapproval in municipal schools.
\end{abstract}

Keywords: School dropout and failure rates; Reinforcement classes; Municipal directors; Contextual questionnaire.

Resumen: Se presentan resultados de investigación que caracterizaron iniciativas de directores municipales de la enseñanza fundamental, vía cuestionario contextual de la Prova Brasil 2015, en lo que se refiere al control del abandono, reprobación, seguimiento de la frecuencia y acciones de refuerzo escolar. El tratamiento estadístico delineó el escenario nacional en lo que se refiere a las 
prácticas declaradas por esos directores, en interlocución con estudios del área. Los datos indican la existencia de acciones para enfrentar el tema que, todavía, presenta índices desafiantes en relación al abandono y a la reprobación en escuelas municipales.

Palabras-clave: Abandono y reprobación escolar; Acciones de refuerzo; Directores municipales; Cuestionario contextual; Prova Brasil.

\section{INTRODUÇÃO}

O artigo tem como propósito apresentar e discutir iniciativas de gestão escolar declaradas por diretores do ensino fundamental das redes municipais brasileiras ao questionário contextual da Prova Brasil de 2015 (PB 2015), no que tange ao controle do abandono e da reprovação, bem como ao acompanhamento da frequência à escola e à oferta de atividades de reforço escolar ${ }^{1}$.

As iniciativas que se voltam às dimensões acima citadas foram especificamente abordadas nos itens de números 41 a 43 , e 45 a 49 do questionário contextual do diretor da PB 2015. Neste ano houve um total de 55.693 respondentes ao referido questionário, sendo $34.502(62 \%)$ de escolas municipais.

Parte-se do pressuposto que a relevância do estudo ora apresentado se pauta no escopo de estudos e debates encetados sobre a avaliação da aprendizagem de alunos desde o final dos anos 1960 e início dos anos 1970 do século XX no Brasil, que configuram um cenário de mais de quarenta anos de discussões no contexto das políticas públicas de educação. De acordo com Ginoza (2018), a literatura da área aponta que o ensino ocupa papel subsidiário no que se refere ao fracasso do aluno, desvinculando-o, muitas vezes, de sua função política e das competências que os docentes devem ter para ensinar e superar situações de fracasso escolar.

Após meados da década de 1980 e, sobretudo, depois da promulgação da Lei de Diretrizes e Bases da Educação Nacional - LDBN n.9394/96 (BRASIL, 1996) , a mudança da escola seriada para a escola organizada em ciclos de aprendizagem logrou centralidade no campo das políticas educacionais na agenda de diferentes programas de governo, implementados em várias redes e sistemas de ensino no Brasil, com o propósito de reverter o quadro de exclusão e fracasso escolar, principalmente nos anos iniciais do Ensino Fundamental. O que se pretendia na proposta de ciclos de aprendizagem era estabelecer uma

1 A pesquisa integra investigação maior - Cenários de Gestão de Escolas Municipais no Brasil financiada pela Fundação Carlos Chagas. Do estudo original participaram Cristiane Machado (Unicamp) e Flávia Obino Werle (Unisinos). 
concepção diagnóstica, contínua e formativa de avaliação para acompanhamento do desenvolvimento do aluno e de sua aprendizagem (LARA; BRANDALISE, 2016; KRAUSE, 2007).

Nessa direção, pesquisas assinalavam que administrar a progressão das aprendizagens significa observar e avaliar alunos em situações de sala de aula, na perspectiva da abordagem formativa, realizando "balanços periódicos [...] essenciais para fundamentar decisões de aprovação ou de orientação necessárias". Nesses termos, "é importante que o professor saiba determinar, interpretar e memorizar momentos significativos", com vistas a superar os desafios de aprendizagem. (PERRENOUD, 2000, p. 49).

No escopo desse debate, coloca-se a relevância da exploração dos itens do questionário contextual da Prova Brasil (2015), referentes ao controle do abandono e da reprovação, bem como ao acompanhamento da frequência à escola e à oferta de atividades de reforço escolar, considerando-se que são medidas de gestão escolar com potencial de lograr sucesso na permanência de alunos na escolaridade básica regular.

Trata-se de estudo de natureza exploratória, que tomou como referência as respostas de diretores municipais declaradas ao questionário da Prova Brasil 2015, tendo em vista que estudos exploratórios propiciam uma aproximação a fatos e/ou dados, sobretudo quando o tema e/ou objeto da pesquisa é pouco explorado, dificultando elaborar "hipóteses operacionalizáveis" (GIL, 2008, p. 27).

O instrumento aplicado aos diretores traz informações que permitem explorar dados de perfil, trajetórias de formação e profissional; participação de famílias e demais membros da comunidade na gestão das unidades escolares; condicionantes de funcionamento das escolas; iniciativas que incidem no acesso e permanência dos alunos na escola com garantia da aprendizagem. Este artigo aborda apenas este último aspecto.

O processamento das respostas dos diretores referentes a cada etapa de ensino foi realizado separadamente, considerando que o foco de análise é a gestão escolar (e não a escola), sob o pressuposto de que práticas de diretores podem ter especificidades no que se refere a cada um dos níveis de ensino ofertados por escolas municipais. Para o processamento, utilizou-se o software IBM SPSS Statistics - 20. O total de questionários tratados nesta pesquisa (43.320) é superior ao número de respondentes de diretores de escolas municipais (34.502) dada a existência de casos em que o mesmo diretor atua em escolas que ofertam anos iniciais do Ensino Fundamental (EFI) e anos finais do Ensino Fundamental (EFII). 
A análise da temática do abandono e da reprovação escolar levou em conta, além das respostas ao questionário contextual da PB 2015, informações obtidas no Censo Escolar e em estudos da área que examinam medidas de governo voltadas para a democratização da escola e do monitoramento de sua qualidade, com foco na reprovação escolar e nas medidas de reforço e controle de frequência.

\section{ABANDONO E REPROVAÇÃO: UM DEBATE NECESSÁRIO}

As taxas de fluxo escolar ${ }^{2}$ monitoram a reprovação e o abandono, com perspectiva de atuação e de controle desses fenômenos, uma vez que refletem resultados que contraditam as perspectivas de democratização da educação.

O cenário delineado pelas informações oficiais, extraídas do Censo Escolar, indica a persistência do abandono e da reprovação na realidade das escolas, mesmo após a adoção de políticas voltadas para a progressão automática e a organização do sistema escolar em ciclos. Os dados constantes ${ }^{3}$ do Censo são apresentados no Quadro 01:

\section{Quadro 01 - Taxas de aprovação, reprovação e abandono no EF em escolas municipais do Brasil de 2007 a 2015}

\begin{tabular}{|c|c|c|c|c|c|c|c|c|c|}
\hline & \multicolumn{3}{|c|}{ Taxa de Aprovação } & \multicolumn{3}{c|}{ Taxa de Reprovação } & \multicolumn{3}{c|}{ Taxa de Abandono } \\
\hline Ano & Total & $\begin{array}{c}\text { Anos } \\
\text { iniciais }\end{array}$ & $\begin{array}{c}\text { Anos } \\
\text { finais }\end{array}$ & Total & $\begin{array}{c}\text { Anos } \\
\text { iniciais }\end{array}$ & $\begin{array}{c}\text { Anos } \\
\text { finais }\end{array}$ & Total & $\begin{array}{c}\text { Anos } \\
\text { iniciais }\end{array}$ & $\begin{array}{c}\text { Anos } \\
\text { finais }\end{array}$ \\
\hline 2015 & 88,7 & 91,6 & 82,8 & 9,0 & 7,1 & 12,9 & 2,3 & 1,3 & 4,3 \\
\hline 2013 & 88,1 & 91,1 & 82,0 & 9,4 & 7,4 & 13,3 & 2,5 & 1,5 & 4,7 \\
\hline 2011 & 86,7 & 89,4 & 81,1 & 10,2 & 8,7 & 13,4 & 3,1 & 1,9 & 5,5 \\
\hline 2009 & 83,8 & 86,3 & 78,6 & 12,2 & 11,1 & 14,7 & 4,0 & 2,6 & 6,7 \\
\hline 2007 & 81,7 & 83,5 & 77,6 & 13,0 & 12,7 & 13,8 & 5,3 & 3,8 & 8,6 \\
\hline
\end{tabular}

Fonte: Indicadores educacionais /BRASIL, 2018.

A partir dessas informações, observa-se que, em 2015, a taxa de abandono para o EFI é de 1,3\%, e, para o EFII é de 4,3\%, resultando em, aproximadamente, $2,3 \%$ das crianças com idades entre 6 e 14 anos deixando a escola nesse ano.

\footnotetext{
2 Consideradas a partir dos índices de aprovação, de retenção e de abandono escolar.

3 A delimitação do período levou em conta o ano de criação do Ideb, 2007, e o ano de coleta das respostas dos diretores ao questionário contextual da PB 2015.
} 
Considerando os dados do período de 2007 a 2015, é possível identificar que há um processo evolutivo e positivo na redução das taxas de abandono escolar. No entanto, observa-se que esses dados ainda são preocupantes quando considerados os seguintes fatores:

i) em números absolutos, considerando-se os dados do Censo Demográfico $^{4}$ de 2010, há um total de 12.034 .004 crianças na faixa etária de 6 a 9 anos $^{5}$. Dessa forma, a taxa de 1,3\% de crianças que abandonaram a escola no EFI, em 2015, corresponde a um total de 156.442 crianças fora da escola. Esse dado se traduz em termos de população equivalente a uma cidade de porte médio ${ }^{6}$. Situação ainda pior está relacionada ao EFII, onde, para uma população de 17.106 .135 crianças de 10 a 14 anos, a taxa de abandono de 4,3\% equivale à existência de 738.168 crianças e jovens fora da escola. Esse número é referente à população de cidades consideradas de porte grande 7 .

ii) observa-se ainda que, ao longo do período, os dados apresentam diminuição dos patamares de redução das taxas de abandono. $\mathrm{O}$ ponto mais alto da retração do abandono escolar é sentido de 2007 para 2009, com queda de 1,2 nos percentuais do EFI e de 1,9 nos percentuais do EFII. No período de 2009 a 2015, os percentuais de retração se vão arrefecendo, ficando em torno de 0,2 nos percentuais do EFI, e de 0,4 nos percentuais do EFII, entre 2013 e 2015.

A situação não é muito diferente em relação às taxas de reprovação. Os dados do Censo Escolar de 2007 a 2015, indicados no Quadro 01, assinalam que não houve evolução significativa dessas taxas no âmbito do EFII. Em 2007, a taxa de reprovação era de 13,8\% e, em 2015, é de 12,9\%, representando uma melhora de 0,9 pontos no percentual em quase uma década. Destacam-se, ainda, oscilações positivas e negativas ao longo desse período, particularmente nos últimos anos considerados.

No que se refere ao EFI, há melhor resultado, considerando-se os anos de 2007 e 2015, quando se identifica uma diminuição em 5,6 pontos percentuais na taxa de reprovação. Essas informações do Censo Escolar, que traduzem a evolução das taxas de reprovação, reforçam análises que apontam para a

4 Utilizam-se, de forma ilustrativa, os dados do Censo Demográfico de 2010, considerando que as taxas de natalidade têm apresentado pequena diminuição nos últimos anos. Nesse sentido, ver: IBGE. Brasil em Síntese. Disponível em: http://brasilemsintese.ibge.gov.br/populacao/taxas-brutas-de-natalidade.html. Acesso em: 12 jul. 2017.

5 Dados retirados da base de dados Sidra do IBGE, disponível em: https://sidra.ibge.gov.br/ tabela/200\#resultado. Acesso em: 14 jul. 2017.

6 Segundo o IBGE são consideradas cidades de porte médio aquelas que possuem entre 100 a 500 mil habitantes.

7 São consideradas cidades de porte grande aquelas que possuem população acima de 500 mil habitantes. Nesse sentido, ver Cidades@, banco de dados do IBGE, disponível em: https://cidades.ibge.gov.br. Acesso em 15 jul. 2017. 
necessidade de políticas específicas para os fenômenos de abandono e reprovação escolar, se, de fato, busca-se a universalização com qualidade da educação básica pública brasileira.

Para Crahay (2006, p. 243), em estudo sobre os efeitos da reprovação, mesmo em países com condições socioeconômicas melhores do que as brasileiras, "parece aceito hoje que o fato de repetir um ano e de recomeçar toda a programação de um curso não ajuda os alunos em dificuldade a superar os obstáculos que os impedem de ser honrosamente bem-sucedidos na escola".

Estudos realizados na década de 1990 já apontavam o grave problema da evasão e da reprovação escolar. Nessa direção, Ribeiro (1991) assinalava que: "Repetência tende a provocar novas repetências, ao contrário do que sugere a cultura pedagógica brasileira de que repetir ajuda a criança a progredir em seus estudos". Gatti, Vianna e Davis (1991), também indicavam que alunos com mais baixo nível socioeconômico estariam propensos à evasão. No entanto, após décadas de pesquisas e debates no campo das políticas públicas de educação, a cultura da reprovação ainda persiste no ambiente escolar (EARP, 2009). Para Gomes (2005, p. 30) "o país confirma de modo geral, portanto, o que diz a literatura internacional: reprovação não é remédio e não raro age como veneno". Ainda, nessa mesma direção, há pesquisas recentes evidenciando que a repetência influencia a evasão (GLÓRIA; MAFRA, 2004; DAMIANI, 2006; LIMA, 2016).

Ademais, há uma tendência em atribuir a responsabilidade pelo fracasso escolar ao aluno e sua família, o que "impede de ver os elementos de interdependência entre o abandono escolar e as instituições escolares, bem como o peso da responsabilidade institucional e comunitária desse fenômeno social" (MARGIOTTA, VITALE, SANTOS, 2014, p. 362).

Alves, Ortigão e Franco (2007) assinalam que, além do capital econômico, os fatores de raça também influenciam na reprovação e no abandono escolar. A literatura recente ainda traz dados que desmistificam a culpabilidade do estudante, quando informa que "[a] evasão e a repetência estão longe de ser problemas relacionados às características individuais dos alunos e de suas famílias. São reflexos da forma como a escola recebe e exerce ação sobre as pessoas dos diferentes segmentos da sociedade" (SILVA FILHO; ARAÚJO, 2017, p. 41).

Nesse sentido, Santos (2013) aponta que há práticas desenvolvidas no contexto escolar, voltadas para a organização de turmas homogeneizadas pelo desempenho estudantil, por exemplo, que são tidas como nefastas. Sobre isso, revela que, "ao proporem formas de combater o problema do fracasso escolar segregando os alunos com baixo desempenho escolar, os sistemas escolares podem estar criando outros" (p. 82). 
Vale destacar, ainda, a discussão encetada por Dubet (2004, p. 544), ao assinalar que em sociedades democráticas deve-se tomar "cuidado para que exista igualdade de oferta escolar, evitando as várias maneiras de 'trapacear', pela parcialidade dos encaminhamentos a trajetórias implícitas". O autor assinala que as unidades deveriam considerar as desigualdades iniciais para compensá-las na direção da discriminação positiva, que, em princípio, pode ter caráter

[...] "negativo", que consiste em evitar a concentração excessiva de alunos idênticos, de guetos da cultura, do dinheiro e da qualidade, de um lado, e de guetos de pobreza e das dificuldades, do outro. Ora, sabemos perfeitamente que a escola, pública ou privada, participa de diversos mecanismos de "mercados" escolares: escolas fortes de um lado, escolas de segunda categoria do outro. A melhor maneira de resistir a esse fenômeno incompatível com uma lógica puramente igualitária é a introdução de mecanismos compensatórios eficazes e centrados nos alunos e em seu trabalho: estudos dirigidos, atividades esportivas e culturais, estabilidade e qualidade das equipes educacionais, preparação específica para concursos e exames... A justiça não consiste apenas em aliviar o trabalho dos professores nas áreas mais difíceis, e sim em tornar esse trabalho mais eficaz (DUBET, 2004, p. 545).

Nesse sentido, a noção de exclusão - outrora tratada como categoria de processos sociais - passa a constituir categoria de processos pedagógicos. Pinto e Silva (2006) discutem a dimensão formativa como fator fundamental na efetivação da aprendizagem necessária ao sucesso da escolarização dos alunos social e culturalmente marginalizados, tendo em vista que a forma de avaliar a aprendizagem dos alunos pode constituir-se em mecanismo excludente, ainda que propostas inovadoras sejam implementadas por medidas governamentais.

A reprovação como efeito de processos pedagógicos que não atendem às necessidades dos alunos é uma dimensão da experiência escolar que pode induzir à desistência de frequência à escola, ou seja, consolida processos de exclusão que extrapolam os muros da escola. A avaliação formativa possibilitaria superar essa dinâmica perversa, mas requer tomada de decisões, registros e análises por parte de professores e equipes de direção, o que configuraria uma prática profissional nos moldes de investigação voltada para ajudar o aluno a apropriar-se dos conhecimentos e habilidades essenciais para inserção na vida e no mundo do trabalho.

Ademais, é importante ressaltar que, em se tratando de educação voltada para a massa da população, o processo de exclusão do sistema deixa de ser um problema educacional e passa a ser um problema social, uma vez que pode indicar marginalização, conforme apontam Margiotta, Vitale e Santos (2014, p. 356): 
Nos casos de abandono escolar, a falta de formação produz efeitos de empobrecimento, que culminam na marginalização, no desvio, no trabalho precário e não qualificado. Isso significa que o fenômeno do abandono escolar é muito mais perigoso numa sociedade na qual se atribui à formação um valor muito alto, em termos de estratégia econômica e social, pois, nesse tipo de sociedade, aqueles que não alcançam o nível de formação desejado estão mais suscetíveis à marginalização.

Em suma, a literatura da área que trata da temática delineia dificuldades para eliminar os processos de exclusão e injustiça social no âmbito escolar, mesmo com a adoção de políticas compensatórias, como a obrigatoriedade escolar de 4 a 17 anos, a organização escolar por sistemas de ciclos, a progressão automática e programas assistenciais como o Bolsa Família ${ }^{8}$.

Nesse sentido, o contexto em que a gestão escolar busca superar índices de abandono e reprovação escolar é caracterizado por tensões junto aos constructos sociais recentes como os ideais de justiça social e democracia, assim como outros, presentes há mais tempo, como meritocracia e controle.

\section{INICIATIVAS DE DIRETORES DECLARADAS NO QUESTIONÁRIO CONTEXTUAL DA PROVA BRASIL (2015): ABANDONO, REPROVAÇÃO ESCOLAR E AÇÕES DE REFORÇO}

Para identificar as iniciativas que os gestores escolares estão adotando para o controle do abandono e da reprovação escolar leva-se em conta as respostas declaradas ao questionário contextual do diretor da PB 2015, especificamente sintetizadas nos itens 41 a 43, e 45 a 49. A questão 41 trata das ações para a redução das taxas de abandono implementadas pela escola e apresenta as seguintes alternativas de respostas: "Não há ação, embora exista o problema"; "Não há ação, porque nesta escola não há esse tipo de problema"; "Sim, mas com resultados ainda insatisfatórios"; "Sim, com resultados satisfatórios" e "Sim, mas ainda não avaliamos o resultado".

As respostas dos gestores indicam que apenas 20,7\% das escolas de EFI e 8,6\% das de EFII não apresentam problema de abandono escolar, o que revela uma situação preocupante em termos de permanência das crianças que ingressam no Ensino Fundamental. Esse dado, conjugado às informações do Quadro 01, explicita a pulverização do abandono escolar no cenário brasileiro, que, apesar de um percentual pequeno - 1,3\% para EFI e 4,3\% para EFII - estaria presente 
em 79,3\% das escolas brasileiras que oferecem os anos iniciais e em $91,4 \%$ das que oferecem anos finais do Ensino Fundamental, indicando a complexidade de controle do problema.

As informações disponibilizadas com base nas respostas do questionário da PB 2015, dada a formulação das questões, não permitem compreender como as escolas vêm lidando com o abandono escolar, mas possibilitam identificar quantas ações vêm desenvolvendo para seu enfrentamento e o sucesso alcançado - ou não - com essas iniciativas. As respostas dos gestores das escolas indicam que somente $32,7 \%$ das escolas de EFI obtiveram resultados positivos com as ações desenvolvidas, enquanto que $42,3 \%$ delas, apesar das ações adotadas, não conseguiram resultados positivos ou não conseguiram avaliar os seus resultados. Ainda, considerando que há $4,2 \%$ de instituições que não conseguiram sequer desenvolver ações nessa direção, tem-se um quadro de ausência ou de dificuldade de desenvolver ações voltadas ao controle do abandono em 46,5\% das instituições. Situação ainda mais preocupante se evidencia nos anos finais do Ensino Fundamental em que apenas $28,4 \%$ das escolas conseguiram resultados positivos para as ações realizadas, enquanto que $57,3 \%$ não conseguiram resultados positivos ou não conseguiram avaliar os resultados das ações implementadas, além de 5,8\% que sequer realizaram ações de controle do abandono. Esses dados apontam um cenário negativo para 63,1\% das escolas de EFII.

As respostas dadas pelos gestores escolares à questão 42 , que versa sobre o desenvolvimento de ações voltadas para a redução das taxas de reprovação, demonstram que as escolas estariam mais empenhadas nessas, do que nas ações voltadas ao combate do abandono escolar, o que pode ser justificado pela centralidade que as políticas em curso atribuem às taxas de aprovação/reprovação como é o caso do Ideb.

Apenas 2,6\% das escolas de EFI e 3,0\% das escolas de EFII não desenvolveram ações de controle da reprovação. No entanto, no que se refere às iniciativas voltadas para o abandono, observou-se que 4,2\% e 5,8\% das escolas referentes, de forma respectiva, aos anos iniciais e finais do ensino fundamental, não desenvolveram medidas para seu controle.

A reprovação também é tida como desafio para um número muito maior de escolas do que o abandono, uma vez que $97,2 \%$ dos diretores de EFI e 98,8\% dos diretores de EFII a consideram um problema. É possível inferir que a centralidade dada pela escola às iniciativas voltadas para a reprovação escolar esteja relacionada, entre outros fatores, à busca por melhores resultados no Ideb. Nesse sentido, Alavarse, Bravo e Machado (2013) observam, a partir de pesquisa realizada em municípios paulistas com melhores resultados no Ideb, movimento de 
valorização da avaliação externa por redes municipais, que estariam configurandose hoje como um dos principais elementos das políticas educacionais no sentido de melhoria da qualidade da educação.

A maioria das escolas aponta que as ações desenvolvidas em torno da reprovação não alcançaram êxito para a maioria, uma vez que apenas 41,1\% dos diretores avaliam que essas tiveram resultados positivos junto ao EFII e 34,5\% avaliaram como satisfatórias as ações voltadas para o EFII.

De forma geral, pode-se inferir que, para os diretores das escolas municipais, apesar das ações implementadas para o controle da reprovação escolar, o alcance de resultados satisfatórios para lograr êxito na superação de índices preocupantes ainda precisa percorrer um longo caminho. Nesse sentido, 53,5\% dos diretores apontam que os resultados ainda são insatisfatórios ou não foram avaliados, o que chega a um percentual de $57,7 \%$, se somarmos as instituições que sequer interferiram no problema, considerando os anos iniciais do Ensino Fundamental.

No que se refere aos anos finais do Ensino Fundamental, é possível observar dados mais preocupantes, uma vez que 61,3\% dos diretores apontaram que não obtiveram resultados satisfatórios para as ações desenvolvidas ou não avaliaram os resultados, que, somados às instituições que não desenvolveram ações de contenção do problema, chegam a 64,5\%.

O quadro que se delineia indica que mais da metade das escolas não está conseguindo atuar na contenção da reprovação, apesar da adoção de iniciativas de organização do ensino em ciclos e de progressão continuada, adotadas por vários sistemas educacionais no Brasil, e da avaliação positiva dessas medidas, conforme apontam estudos da área (ALAVARSE, 2009; SOUSA; BARRETO, 2013; LIMA, 2016).

Entre as ações que estariam relacionadas ao combate do fracasso escolar, constantes das questões 43 e de 45 a 49 do questionário da Prova Brasil 2015, estão: reforço escolar, conversas com os alunos que faltam às aulas, envio de aviso aos responsáveis e visita de pessoa da escola a casa do aluno para verificar as faltas.

Pode-se considerar que a opção do MEC, ao indicar essas ações como alternativas de respostas possíveis de serem assinaladas pelos respondentes, esboça a intencionalidade de induzir as ações das escolas em duas direções: uma voltada para reforço da aprendizagem e outra focada no controle da frequência escolar.

Sobre o reforço escolar, conforme as respostas dadas à questão 43, observa-se que esse constitui uma prática pedagógica adotada pela maior parte das escolas, com $89,2 \%$ dos diretores apontando o uso desse recurso no contexto 
do EFI e 88,1\%, no EFII. Ressalta-se, ainda, que essa medida é utilizada em proporções similares, para os dois ciclos do ensino fundamental, constituindo-se como ação comum de intervenção da escola na busca por melhoria de qualidade.

Nesse sentido, Freitas, Baruffi e Real (2011a, p. 18) indicam que entre as 10 medidas de política institucional comuns às redes que obtiveram os melhores resultados do Ideb ${ }^{9}$, em Mato Grosso do Sul, no período de 2005 a 2009, estava o "atendimento sistemático prestado aos alunos com baixo aproveitamento escolar no contra turno escolar", ou seja, redes com destaque no Ideb adotaram, como ponto comum, o reforço escolar. As autoras também apontam que essas redes têm como primeira iniciativa o cuidado com infraestrutura, pois se configura como condicionante, uma vez que "[...] programas de atendimento complementar no contra turno deixam de ser ofertados ou de ter prosseguimento por falta de espaço físico e de professores" (FREITAS, BARUFFI, REAL, 2011, p. 214).

Esses dados sinalizam que o reforço escolar tem sido uma das medidas de política institucional praticadas pelas redes municipais de educação, como estratégia de controle do fracasso escolar, mas que essas ações têm limites no que se refere às condições de infraestrutura, que por sua vez dependem de financiamento específico, o que pode interferir em sua frequência e permanência. Talvez, esse seja um dos motivos que impliquem o baixo êxito das medidas adotadas pelas escolas.

Quanto às demais estratégias utilizadas, as respostas dos diretores permitem sinalizar que as ações se concentram em: a) conversar com os alunos que faltam às aulas, uma vez que $93 \%$ dos diretores informam que "frequentemente", "sempre" ou "quase sempre" realizam conversas com os alunos, no que se refere ao EFI e 88,8\% ao EFII; e b) avisar os responsáveis sobre as faltas dos filhos, medida adotada por 95,6\% das escolas de EFI e 94,4\% das escolas de EFII. Ainda, 38,6\% das escolas de EFI e 33,7\% das de EFII enviam pessoa à casa do aluno para verificar suas faltas de forma frequente e com regularidade.

Observa-se que a estratégia mais apontada pela escola como alternativa para o controle da frequência escolar é avisar os responsáveis pelas faltas dos filhos. O questionário sinaliza três indicações ou formas de avisar os responsáveis: 1) aviso pelas faltas dos filhos, por comunicação da escola; 2) chamadas dos responsáveis para reunião para tratar do assunto; 3) chamadas dos responsáveis à escola para conversar individualmente. 
Nesse caso, a tendência da escola é avisar o responsável por comunicação, uma vez que essa alternativa recebeu $95,6 \%$ das indicações de regularidade nessa atividade, considerando as expressões: "frequentemente", "sempre" ou "quase sempre". O mesmo ocorre nos anos finais do Ensino Fundamental, havendo apenas uma pequena oscilação no percentual, que ficou em 94,4\%.

As demais opções tiveram uma incidência menor, sendo que o aviso para reuniões de pais é ainda maior do que os avisos para conversas individuais. Os avisos para reuniões de pais ocorrem com percentual de 91\% no EFI e 90,9\% no EFII; já os avisos individuais tiveram incidência de 89,1\% no EFI e de 88,3\% no EFII.

Esses dados explicitam que, em relação à frequência, as escolas adotam estratégias semelhantes para os anos iniciais e finais do ensino fundamental, em proporções similares e, usualmente, recorrem ao envio de aviso aos pais ou responsáveis. Essa medida ocorre de forma mais incisiva por meio de comunicações da escola. A segunda forma mais apontada pelos diretores é a chamada para reuniões com os pais; a terceira estratégia seria o chamado para conversa individual; e por último, ou seja, a estratégia menos utilizada, é a visita à casa dos estudantes.

Em outras palavras, a escola demanda a presença da família na escola, por meio de envio de bilhetes e de chamadas para reuniões de pais e mestres. Contudo, ressalte-se que, apesar do baixo percentual de escolas que desenvolvem visitas às casas de alunos, há indicações na literatura de iniciativas adotadas por alguns sistemas de ensino municipais que buscam desenvolver políticas (ações, projetos ou programas) de integração escola-família, viabilizando condições para o envio de pessoas da escola às casas dos estudantes, como forma de combate à reprovação e ao abandono escolar. Podem ser citados como exemplos de adoção dessas medidas: Taboão da Serra (GUARÁ, 2009), Bebedouro (VIEIRA, RAGINATO, MORAES, 2009) Belo Horizonte (ZELMANOVITS, 2009) e Sobral (INEP, 2005).

Sobre o alto índice de faltas dos alunos, os dados evidenciam que essa situação não ocorre em 54,3\% das escolas de EFI e 46,9\% de EFII e que ocorre pouco em 30,4\% das escolas de EFI e 33,3\% de EFII. Ou seja, este parece ser um problema que não afeta $84,7 \%$ dos anos iniciais e $80,2 \%$ dos nos finais.

A essa problemática estão relacionadas as proposições constantes no Estatuto da Criança e do Adolescente (ECA), que prevê ações específicas para o poder público, a família e os dirigentes escolares, nos seguintes termos: 
Art. 54. [...] $3^{\circ}$ Compete ao poder público recensear os educandos no Ensino Fundamental, fazer-lhes a chamada e zelar, junto aos pais ou responsável, pela frequência à escola (sic). [...] Art. 55. Os pais ou responsável têm a obrigação de matricular seus filhos ou pupilos na rede regular de ensino. [...] Art. 56. Os dirigentes de estabelecimentos de ensino fundamental comunicarão ao Conselho Tutelar os casos de: [...] II - reiteração de faltas injustificadas e de evasão escolar, esgotados os recursos escolares; [...] III - elevados níveis de repetência (BRASIL, 1990).

Em síntese, as respostas dos diretores escolares junto à PB 2015 sinalizam que diretores escolares, para além do cumprimento da legislação, buscam adotar iniciativas de vertente democratizante voltadas para o controle do abandono e a da reprovação escolar. No entanto, o êxito de suas ações tem sido limitado diante do cenário ainda emblemático no campo de intencionalidades e condicionantes presentes na escola, considerando-se a complexidade do fenômeno.

\section{CONSIDERAÇÕES}

Os resultados do estudo corroboram dados que vêm sendo apontados em torno do tema, assinalando a persistência do fracasso escolar, em função de inúmeros fatores, dentre os quais, destaquem-se: a existência de concepções heterogêneas e, muitas vezes, equivocadas, dos profissionais da educação acerca da ação avaliativa; a necessidade de formação adequada em cursos superiores e de qualidade para os professores; a ausência de programas de formação continuada que discutam concepções de avaliação e formas inovadoras de abordagem do conteúdo; a necessidade de superação da noção de avaliação escolar como elemento classificatório imposto pela escola, predominantemente formal, e cujos objetivos estão pautados na quantificação e/ou verificação da aprendizagem, limitadas a julgamentos que levam apenas à aprovação ou reprovação, com base nas notas; a predominância de orientação, nas políticas públicas, de estímulos aos resultados finais das avaliações e não aos processos diagnósticos; as repercussões das avaliações de larga escala que colocam ênfase nos resultados em detrimento da reflexão sobre o cotidiano dos processos de ensino e de aprendizagem; condições inadequadas de infra estrutura nas escolas, tanto no que se refere a materiais didático-pedagógicos como no provisionamento estável de quadros de profissionais (LEMOS, SÁ, 2013; BROCANELLI, SABIA, DÁTILO, 2013; SOUZA, ZIBETTI, 2015; LOUZADA, MARQUES, 2016).

Com base nos dados, pode-se inferir que diretores de escolas municipais têm implementado ações voltadas para o controle do abandono e da reprovação escolar por meio de programas de reforço escolar, conversas com os estudantes, 
envio de comunicados à família dos estudantes, convites à família para reuniões escolares, convite à família para conversas individuais e, em menor quantidade, envio de pessoas da escola à casa dos estudantes.

As respostas declaradas no questionário contextual da Prova Brasil (2015) indicam que as ações registradas não têm conseguido diminuir de forma significativa e abrangente o problema, uma vez que índices ainda permanecem alarmantes e desafiadores, conforme discutido anteriormente com base nos estudos da área e em dados oficiais, sobretudo num país com dimensões continentais como o Brasil ${ }^{10}$.

A organização escolar em ciclos e a progressão automática têm sido algumas opções de redes e sistemas de ensino municipais, porém, não abrangem o conjunto das redes de escolas e não alteram o quadro nacional, conforme aponta o Censo Escolar divulgado em 2017, ao assinalar que muitos alunos estão na escola, porém, na idade escolar errada. Os dados do INEP indicam que isso ocorre tanto pela reprovação quanto pela alta taxa de abandono escolar, principalmente após o Ensino Fundamental. O órgão indica também que nos anos iniciais, há menores taxas de distorção nos estados de Minas Gerais, Mato Grosso e São Paulo, onde, respectivamente, 69,1\%, 61,7\% e 56,6\% dos municípios apresentaram taxas menores que 5\%. Já nos anos finais, há uma piora nas estatísticas, em que apenas cinco estados têm algum município com taxas de distorção idade-série inferior a $5 \%$. Os indicadores de aprovação também caíram nessa etapa ${ }^{11}$.

Mesmo as diretrizes e medidas políticas de dimensão normativa, como a obrigatoriedade constitucional do ensino dos 4 aos 17 anos, o direito público subjetivo, as atribuições dadas à família e à escola, constantes no ECA, assim como as políticas sociais - o caso do Programa Bolsa Família -, não têm conseguido erradicar efetivamente o fracasso escolar.

Por fim, o presente estudo aponta a necessidade de implementação e acompanhamento de medidas mais eficazes voltadas à superação dos índices ora apresentados, sobretudo se considerarmos a discussão sobre justiça social no âmbito escolar.

\footnotetext{
10 O país tem 184,1 mil escolas e a maior parte (112,9 mil, o que equivale a dois terços) é de responsabilidade municipal. Do total de escolas, 116 mil instituições de ensino oferecem ensino fundamental com 48,6 milhões de alunos matriculados.

11 http://inep.gov.br/educacao_basica/educacenso/documentos/2018/boletim_censo_escolar_ n11_fev2018.pdf. Acesso em 28/03/2018.
} 


\section{REFERÊNCIAS}

ALAVARSE, Ocimar Munhoz. A organização do ensino fundamental em ciclos: algumas questões. Revista Brasileira de Educação, Rio de Janeiro, v. 14, n. 40, p. $35-50$, jan./abr. 2009.

ALAVARSE, Ocimar Munhoz; BRAVO, Maria Helena; MACHADO, Cristiane. Avaliações externas e qualidade na educação básica: articulações e tendências. Estudos em Avaliação Educacional, São Paulo, v. 24, n. 54, p. 12-31, jan./abr. 2013

ALVES, Fátima; ORTIGÃO, Isabel; FRANCO, Creso. Origem social e risco de repetência: interação raça-capital econômico. Cadernos de Pesquisa, v. 37, n. 130, p. 161-180, jan./abr. 2007.

BRASIL. Ministério de Educação e Cultura. LDB - Lei $\mathbf{n}^{\mathbf{0}}$ 9394/96, de 20 de dezembro de 1996. Estabelece as diretrizes e bases da Educação Nacional. Brasília: MEC, 1996.

. Lei No 10.836, de 9 de janeiro de 2004. Cria o Programa Bolsa Família e dá outras providências. Brasília: Palácio do Planalto, 2004. Disponível em: < http://www.planalto.gov.br/ccivil_03/_ato2004-2006/2004/lei/110.836.htm >. Acesso em: 16 nov. 201

. Lei no 8.069, de 13 de julho de 1990. Dispõe sobre o Estatuto da Criança e do Adolescente e dá outras providências. Diário Oficial [da] República Federativa do Brasil, Brasilia, DF, 16 jul. 1990. Disponível em: <http://www. planalto.gov.br/ccivil_03/LEIS/L8069.htm\#art266>Acesso em: 14 nov. 2017.

Prova Brasil. Apresentação. Disponível em: http://portal.mec.gov. br/prova-brasil. Acesso em 10/03/2016.

BROCANELLI, Cláudio Roberto; SABIA, Cláudia Pereira de Pádua; DÁTILO, Gilsenir Maria Prevelato de Almeida - O desconhecimento do professor sobre avaliação e o plano de desenvolvimento da escola. Comunicações, Piracicaba, ano 21, n.2, p.17-32, 2013.

CRAHAY, Marcel. É possível tirar conclusões sobre os efeitos da repetência? Cadernos de Pesquisa, São Paulo, v. 36, n. 127, p. 223-246, abr. 2006. 
DAMIANI, Magda Floriana. Discurso pedagógico e fracasso escolar. Ensaio: avaliação e política pública de Educação, Rio de Janeiro, v.14, n.53, p. 457 478, out./dez. 2006.

DUBET, François. O que é uma escola justa? Cadernos de Pesquisa, São Paulo, v. 34, n. 123 , p. 539-555, dez. 2004.

A escola e a exclusão. Cadernos de Pesquisa, São Paulo, n. 119, p. 29-45, 2003.

EARP, Maria de Lourdes Sá. A cultura da repetência em escolas cariocas. Ensaio: aval. pol. públ. Educ., Rio de Janeiro, v. 17, n. 65, p. 613-632, out./dez. 2009.

FREITAS, Dirce Nei Teixeira de; BARUFFI, Alaíde Maria Zabloski; REAL, Giselle Cristina Martins. Resultados positivos do Ideb em redes escolares municipais: evidências de estudo exploratório. REUNIÃO ANUAL DA ASSOCIAÇÃO NACIONAL DE PESQUISA E PÓS-GRADUAÇÃO EM EDUCAÇÃO, 34., 2011, Natal. Trabalhos... Rio de Janeiro: ANPEd, 2011. Disponível em: < http://34reuniao.anped.org.br/images/trabalhos/GT05/GT05-400\%20int.pdf >. Acesso em: 23 ago. 2017.

O contexto, as políticas educacionais e o Ideb. In: FREITAS, Dirce Nei Teixeira de; REAL, Giselle Cristina Martins (Orgs). Políticas e monitoramento da qualidade do ensino fundamental: cenários municipais. Dourados: UFGD, 2011, p. $201-224$.

GATTI, Bernardete A.; VIANNA, Heraldo Marelim; DAVIS, Cláudia. Problemas e impasses da avaliação de projetos e sistemas educacionais: dois casos brasileiros. Estudos em Avaliação Educacional, São Paulo, n. 4 p. 7-26, jul.-dez. 1991.

GIL, Antonio C. Métodos e técnicas de pesquisa social. 6a ed. São Paulo. Atlas, 2008.

GINOZA, Marli. Avaliação da Aprendizagem na Educação Básica produção em periódicos científicos (2008-2017). Dissertação de Mestrado. Universidade Cidade de São Paulo, 2018, 98F. 
GOMES, Candido Alberto. Desseriação escolar: alternativa para o sucesso?. Ensaio: avaliação e política pública de Educação, Rio de Janeiro, v. 13, n. 46, p. 11-38, mar. 2005.

GLÓRIA, Dília Maria Andrade; MAFRA, Leila de Alvarenga. A prática da nãoretenção escolar na narrativa de professores do Ensino Fundamental: dificuldades e avanços na busca do sucesso escolar. Educação e Pesquisa, São Paulo, v. 30, n. 2, p. 231-250, maio/ago. 2004.

GOMES, Candido Alberto. Desseriação escolar: alternativa para o sucesso? Ensaio: avaliação e política pública de Educação, Rio de Janeiro , v. 13, n. 46, p. 11-38, mar. 2005.

GUARÁ, Isa Maria F. Rosa. Com os professores visitadores, a escola vai à família. Cadernos CENPEC, São Paulo, v. 4, n. 6, p. 56-58, 2009.

INEP - Instituto Nacional e Estudos e Pesquisas Educacionais Anísio Teixeira. Indicadores Educacionais. Brasília: Inep, 2018. Disponível em: < http://portal. inep.gov.br/web/guest/sinopses-estatisticas-da-educacao-basica >. Acesso em: 14 mar. 2018.

Vencendo o Desafio da Aprendizagem nas Séries Iniciais: A Experiência de Sobral/CE. Brasília: INEP, 2005. Disponível em: < http://portal. inep.gov.br/documents/186968/488938/Vencendo+o+desafio + da + aprendiz agem + nas + s $\%$ C3\%A $\%$ ries + iniciais + a + experi $\%$ C3\%AAncia + de + Sobral-CE/ a7de6174-3f52-49fe-b81c-9f40372761a3?version=1.0 >. Acesso em: 12 set. 2017.

KRAUSE, Helvia Tomaselli. Um possível caminho para a construção de formas de registro da avaliação formativa. Itajaí: Contrapontos, vol. 7, n.1, p.71-90, 2007.

LARA, Viridiana Alves de; BRANDALISE, Mary Ângela T. Avaliação da aprendizagem na escola organizada em ciclos: concepções de professores. Est. Aval. Educ., S. Paulo, v.27, n.64, p.36-68, 2016

LEMOS, Paulo Santana; SÁ, Luciana Passos. A avaliação da aprendizagem na concepção de professores de química do ensino médio. Revista Ensaio - Belo Horizonte, v.15, n.03, p. 53-71, 2013. 
LIMA, Maria de Fátima Magalhães de. Correção de Fluxo na Rede Pública Municipal do Rio de Janeiro (2009-2014): aspectos da política e as trajetórias dos alunos. 2016. 226 f. Tese (Doutorado em Educação) - Pontifícia Universidade Católica do Rio de Janeiro, Rio de Janeiro, 2016.

LOUZADA, Virgínia; MARQUES, Roberto. Políticas de regulação para educação no Brasil: interfaces entre currículo, avaliação e formação docente. Revista e-Curriculum, SP, v.13, n. 04, p.711-732, 2015

MARGIOTTA, Umberto; VITALE, Gabriella; SANTOS, Jácia Soares dos. O fenômeno do abandono escolar na Europa do novo milênio: dados, políticas, intervenções e perspectivas. Cadernos Cedes, Campinas, v. 34, n. 94, p. 349-366, set.- dez., 2014

OLIVEIRA, Romualdo Portela de; ARAUJO, Gilda Cardoso de. Qualidade do ensino: uma nova dimensão da luta pelo direito à educação. Rev. Bras. Educ., Rio de Janeiro, n. 28, p. 5-23, abr. 2005.

PARO, Vitor. Reprovação escolar: renúncia à educação. 2. ed. São Paulo: Xamã, 2003.

PERRENOUD, Philippe. Dez novas competências para ensinar. Tradução Patrícia Chittoni Ramos. Porto Alegre: Artes Médicas Sul, 2000.

PINTO Neusa Bertoni; SILVA, Cláudia Mara Soares da. Avaliação da Aprendizagem e exclusão social. Diálogo Educacional, Curitiba, 2006, v.6. n.19, p.111-126.

RIBEIRO, Sérgio Costa. A pedagogia da repetência. Estudos avançados, São Paulo, v. 5, n. 12, p. 07-21, Ago. 1991.

SANTOS, Mauro Pedro dos. Programa PIC da rede municipal de ensino de São Paulo: superação do fracasso escolar? 2013. Dissertação (Mestrado em Educação) - Universidade Cidade de São Paulo, São Paulo, 2013, 102F.

SILVA FILHO, Raimundo Barbosa; ARAÚJO, Ronaldo Marcos de Lima. Evasão e abandono escolar na educação básica no Brasil: fatores, causas e possíveis consequências. Educação por Escrito, Porto Alegre, v. 8, n.1, p. 3548, jan.-jun. 2017. 
SOUSA, Sandra Maria Zákia Lian; BARRETO, Elba Siqueira de Sá (Coord.). Ciclos e progressão escolar (1990-2002). Brasília, DF: MEC/Inep, 2013.

SOUZA, Flora Lima Farias de Souza; ZIBETTTI, Marli Lúcia Tonatto. Uma escola, múltiplos olhares: avaliação e recuperação no cotidiano escolar. Práxis Educativa, Ponta Grossa, v.11, n.2, p.394-409, 2016.

VIEIRA, Adriano; RAGINATO, Maria José; MORAES, Marilda Ferraz Ribeiro de. Família, comunidade e escola se encontram. Cadernos CENPEC, São Paulo, v. 4, n. 6, p. 111-117, 2009.

ZELMANOVITS, Maria Cristina. Em busca de familiaridades. Cadernos CENPEC, São Paulo, v. 4, n. 6, p. 20 - 26, 2009.

GISELLE CRISTINA MARTINS REAL possui graduação em Pedagogia pela Universidade Federal de Mato Grosso do Sul - UFMS (1988), graduação em Direito pelo Centro Universitário da Grande Dourados (1989), mestrado em Educação pela Universidade UFMS (2000) e doutorado em Educação pela Universidade de São Paulo - USP (2007). Realizou, em 2011, estágio de pósdoutoramento na USP ,e na UFMS, no período de 2017/2018. Foi pró-reitora de ensino de graduação da UFGD, no período de 2011 a 2015. Atualmente é professora associada da Universidade Federal da Grande Dourados, atuando na graduação e na pós-graduação stricto sensu, orientando mestrado e doutorado. Tem experiência na área de Educação, com ênfase em Política Educacional, atuando principalmente com os temas avaliação e educação superior. E-mail: gcreal@terra.com.br

JOSÉ DA SILVA SANTOS JUNIOR possui Mestrado em Educação pela Universidade Federal da Grande Dourados, Especialização em Metodologia do Ensino Superior (2011) e Educação a Distância (2012), pelo Centro Universitário da Grande Dourados, graduação em Ciências Biológicas (Licenciatura) pela Universidade Estadual de Mato Grosso do Sul (2007). Atualmente é Técnico em Assuntos Educacionais da Universidade Federal da Grande Dourados. E-mail: josejunior_ss@yahoo.com.br

SANDRA MARIA ZÁKIA LIAN SOUSA possui graduação em Pedagogia pela Universidade Presbiteriana Mackenzie (1975), mestrado em Educação: Currículo, pela Pontifícia Universidade Católica de São Paulo (1986) e doutorado em Educação pela Universidade de São Paulo (1994). Atualmente é professora colaboradora da Universidade de São Paulo. Tem experiência na área de Educação, com ênfase em Política, Planejamento e Avaliação Educacional, atuando principalmente nos seguintes temas: politica educacional, avaliação educacional, avaliação escolar e ensino.E-mail: sanzakia@usp.br 
ANGELA MARIA MARTINS é graduada em Ciências Sociais e Políticas. Mestre em Educação pela Universidade de São Paulo - USP. Doutora em Educação pela Universidade Estadual de Campinas - UNICAMP. Realizou pós-doutorado com bolsa da Coordenação de Aperfeiçoamento de Pessoal de Nível Superior - Capes - no Instituto de Psicologia e Ciências da Educação da Universidade de Lisboa (2008), na área de políticas públicas educacionais. Em 2016 realizou estágio na Universidade Nova de Lisboa, com Bolsa de Estágio de Pesquisa no Exterior (senior), da Fundação de Amparo à Pesquisa do Estado de São Paulo - Fapesp. Desde 1996 é pesquisadora da Fundação Carlos Chagas na área de política e gestão da educação. Atualmente é professora do Programa de PósGraduação em Educação na Universidade Cidade de São Paulo e do Mestrado Profissional Formação de Gestores Educacionais na mesma instituição. Tem estudado principalmente os seguintes temas: políticas educacionais e gestão da educação básica; metodologias de pesquisa; trajetórias e identidade profissional de diretores e professores. E-mail: ange.martins@uol.com.br

MARIA HELENA DE AGUIAR BRAVO é doutoranda em Educação na Faculdade de Educação da Universidade de São Paulo (FEUSP) com bolsa de estudos FAPESP. Mestra em Educação (2017), bacharel e licenciada em Pedagogia (2013) pela Faculdade de Educação da Universidade de São Paulo (FEUSP). Foi estagiária na Ação Educativa de 2010 a 2012, atuou como Assistente de Projetos na Campaña Latinoamericana por el Derecho a la Educación (CLADE) de 2013 a 2015 e em conjunto com a Coordenadoria de Pesquisa do Centro de Estudos e Pesquisas em Educação, Cultura e Ação Comunitária (Cenpec) de 2013 a 2015. Atua como assistente de pesquisas na Fundação Carlos Chagas desde 2015. Participante do Grupo de Estudos e Pesquisas em Avaliação Educacional (Gepave) na FEUSP. E-mail: mh.bravo@yahoo.com.br 